\title{
Relationships between micronutrient intake and biochemical indicators of nutrient adequacy in a 'free-living' elderly UK population
}

\author{
BY ANGELA L. BAILEY ${ }^{1}$, SUSAN MAISEY ${ }^{2}$, SUSAN SOUTHON ${ }^{1}$, \\ ANTHONY J. A. WRIGHT ${ }^{1}$, PAUL M. FINGLAS ${ }^{1}$ AND ROBERT A. FULCHER ${ }^{2}$ \\ ${ }^{1}$ Institute of Food Research, Norwich Research Park, Colney, Norwich NR4 7UA \\ ${ }^{2}$ Department of Medicine for the Elderly, West Norwich Hospital, Norwich NR2 $3 T U$
}

(Received 6 July 1995 - Revised 28 May 1996 - Accepted 3 July 1996)

\begin{abstract}
Nutritional assessments are frequently based on amounts of nutrients consumed. In the present paper the usefulness of nutrient intake data for assessing nutrient adequacy is examined in an elderly British population. Subjects were 'free-living' elderly aged 68-90 years (sixty men, eightyfive women) in Norwich. Forty-two of forty-nine surviving males and sixty-seven of seventy-nine surviving females were reassessed after 2 years. With few exceptions, estimated micronutrient intake was not statistically predictive of biochemical measures of nutrient adequacy. Initial biochemical measures of nutritional adequacy were compared with those found 2 years later in an attempt to assess whether initial biochemical assessment was predictive of the 'longer term' situation. Biochemical measurements at the start of the study were correlated to the same measurements made 2 years later for: serum ferritin, haemoglobin and erythrocyte count, wholeblood Se-glutathione peroxidase ( $E C$ 1.11.1.9; males only), plasma $\mathrm{Cu}$, alkaline phosphatase ( $E C$ 3.1.3.1), ascorbic acid, vitamin $B_{6}$ (pyridoxal-5-phosphate), folate and vitamin $B_{12}$, total erythrocyte thiamin (males only), riboflavin (erythrocyte glutathione reductase $(E C$ 1.6.4.1) activation coefficient): but not for: erythrocyte Cu-superoxide dismutase $(E C$ 1.15.1.1) or plasma $\mathrm{Zn}$. Either only small changes, or no changes, in mean values were seen over the 2 years for most of the biochemical measures. One exception was a large increase in plasma folate. The only important 'negative' features seen at 2-year follow up were a large fall in serum ferritin concentration and a large increase in the activity of two antioxidant defence enzymes, superoxide dismutase and glutathione peroxidase. As judged by currently accepted biochemical deficiency threshold values, a small proportion of subjects were possibly at risk of $\mathrm{Fe}(3 \%$ men; $1 \%$ women), folate $(7 \%, 3 \%)$, thiamin $(12 \% ; 3 \%)$ and vitamin $\mathrm{C}(15 \% ; 17 \%)$ deficiency. Many more appeared to be at risk of vitamin $B_{6}(42 \% ; 47 \%)$ and riboflavin $(77 \% ; 79 \%)$ deficiency. It was concluded that the requirements of the elderly for vitamins $B_{1}, B_{2}$ and $C$, and the biochemical deficiency threshold values used to indicate vitamin $B_{6}$ deficiency, need review.
\end{abstract}

Micronutrients: Dietary survey: Nutrient status: Elderly

In a previous study, which examined relationships between micronutrient intake and appropriate biochemical measurements in an adolescent population (Southon et al. 1994), it was concluded that total nutrient intake within the ranges encountered (calculated from written, weighed records of everything consumed every 6th day for 7 weeks, or measured by direct analysis of duplicate weighed diets) rarely predicted biochemical indices of nutrient adequacy in this population. Using nutrient intake data calculated from food tables (Paul \& Southgate, 1978; Wiles et al. 1980; Tan et al. 1985; Holland et al. 1988, 1989), only two significant relationships between intake and biochemical values were observed in the adolescent subjects; vitamin $\mathrm{C}$ intake and plasma ascorbic acid (PAA) in boys and riboflavin intake and erythrocyte glutathione reductase $(E C$ 1.6.4.1) activation coefficient 
(EGR-Ac) in girls. Using data obtained from direct analysis of diets, the correlation between vitamin $C$ intake and PAA was significant for both sexes, the relationship between riboflavin intake and EGT-Ac in girls disappeared, whilst vitamin B $_{6}$ intake and plasma pyridoxal-5-phosphate (PLP) concentration in boys became significantly correlated (Southon et al. 1994). The present paper reports results of a similar study which examined relationships between micronutrient intake and biochemical indices in a free-living elderly population (sixty males, eighty-five females, $68+$ years of age). The usefulness of intake and biochemical measurements for the assessment of nutritional adequacy and nutrient deficiency in this age group is considered and discussed. Male and female subjects are considered separately and the results compared. In addition, biochemical measurements obtained at the start of the study are compared with those obtained 2 years later, to determine whether the initial values are predictive in the longer term.

\section{MATERIALS AND METHODS}

\section{Subjects}

The study was approved by the Institute of Food Research's Ethics Committee. Free-living elderly subjects (sixty male, eighty-five female) aged 68-90 years were recruited between April 1990 and June 1991 from two general practices in Norwich. Volunteers lived relatively independently in their own homes. Recruitment methods and response rates are described fully elsewhere (Maisey et al. 1995). Mean values for age, height and weight were as follows: age, males 74.4 (range 68-87) years, females 74.6 (range 68-90) years; height, males 1.67 (range 1.50-1.84) m, females 1.56 (range 1.41-1.72) m; weight, males 71.5 (range $46.0-92.0$ ) $\mathrm{kg}$, females 62.3 (range $41.0-84.0$ ) $\mathrm{kg}$. These values, together with smoking behaviour and percentage of subjects taking prescribed medicines, are discussed further elsewhere (Wright et al. 1995).

Assessment at recruitment included medical history, medication, anthropometric and physiological measurements in addition to the dietary intake and biochemical measurements described here.

All surviving subjects were contacted again 2 years after recruitment and invited to reattend or be visited at home for a repeat set of anthropometric measurements and a further fasting blood sample. Some of the subjects (eleven men, six women) were known to have died and seven men and eleven women did not wish to participate again. One woman had moved from the area but was ascertained to be alive. The remaining subjects (forty-two men, sixty-seven women) were reassessed using the same methods as at recruitment. The initial biochemical measurements obtained for the surviving subjects and those who had died during the course of the study were compared.

\section{Measurement of dietary intake}

The methods used for the capture of dietary intake data were tailored to the capability of each individual subject so as to obtain the most accurate information. Some subjects weighed all of their food, some used a combination of direct weighing and the use of household measures and the rest exclusively used household measures.

Subjects aged 68-73 years, completed $7 \mathrm{~d}$ of weighed record and/or estimated record (household measures) between mid-May and mid-August 1990. This was usually over consecutive days but, if not, always included each day of the week. In all $31 \%$ of this age group directly weighed all of their food, $57 \%$ used household measures and $12 \%$ used a combination of methods. Subjects were visited by a fieldworker three times during the period of dietary recording. Dietary records, scales and types of household measures used were checked, any additional or missing information obtained, records annotated and 
completed records collected. In addition, each subject (including those in the more aged group which is described later) was given a telephone number which would put them in touch with someone who could assist with queries on the days when a visit from the fieldworker was not planned.

Subjects aged 74+ years, completed $5 \mathrm{~d}$ of weighed record and/or estimated record (household measures), similar to the 'younger' elderly group, between November 1990 and June 1991 including three week days and two weekend days of the same week. Subjects were visited three times over the period of dietary recording. In addition subjects were asked to record their activities and what they had eaten over the past $24-48 \mathrm{~h}$. Considerably more interviewer prompting and extensive annotation of the weighed records was required for this age group than for younger subjects. Only $7 \%$ of this group directly weighed all their food, $90 \%$ used household measures and the remaining $3 \%$ used a combination of methods.

Nutrient composition was calculated using McCance and Widdowson's The Composition of Foods (Paul \& Southgate, 1978) together with Immigrant Food Supplement (Tan et al. 1985), Additional Foods (Wiles et al. 1980), Cereals and Cereal Products (Holland et al. 1988), Milk Products and Eggs (Holland et al. 1989), Food Portion Sizes (Crawley, 1988) and our own data collected from the present and previous studies (J. M. Loughridge and A. D. Walker, unpublished results).

Fasting ( $12 \mathrm{~h}$ ) venous blood was collected by venepuncture from the antecubital fossa during the fortnight preceding dietary assessment.

Blood samples were divided immediately after collection as follows: (a) $1.5 \mathrm{ml}$ unheparinized whole blood was transferred to $2 \mathrm{ml}$ microcentrifuge tubes for serum ferritin analysis and within $2 \mathrm{~h}$ serum was separated by centrifugation at $8800 \mathrm{~g}$ for $4 \mathrm{~min}$ and stored at $-40^{\circ}$ until analysis; (b) $3.5 \mathrm{ml}$ whole blood was transferred to potassium-EDTA tubes for haemoglobin analysis and a full blood count at Norfolk and Norwich Hospital (N and $\mathrm{N}$ ); (c) $12 \mathrm{ml}$ whole blood was transferred to a heparinized tube for micronutrient and lipid analysis, this sample was divided as follows: (1) within $2 \mathrm{~h}$ of collection $1.5 \mathrm{ml}$ was centrifuged at $8800 \mathrm{~g}$ for $4 \mathrm{~min}$, the plasma separated and stabilized by addition of an equal volume of metaphosphoric acid (60 g/l aqueous) and then either placed on ice for immediate analysis of ascorbic acid or stored under liquid $\mathrm{N}_{2}$ for up to 1 week before analysis; (2) $100 \mu 1$ was taken for glutathione peroxidase assay; (3) the remaining whole blood was centrifuged at $750 \mathrm{~g}$ for $10 \mathrm{~min}$ at $4^{\circ}$, the plasma removed and subsamples of plasma taken for measurement of alkaline phosphatase (EC 3.1.3.1) activity $(200 \mu \mathrm{l}), \mathrm{Zn}$ and $\mathrm{Cu}(2 \mathrm{ml})$, PLP $(500 \mu \mathrm{l})$, vitamin $\mathrm{B}_{12}$ and folate $(500 \mu \mathrm{l})$, vitamin $\mathrm{D}(100 \mu \mathrm{l})$, cholesterol, $\mathrm{HDL}$ and $\mathrm{LDL}$ and triacylglycerols $(1 \mathrm{ml})$. Remaining packed erythrocytes were washed thoroughly with an equal volume of cold $\left(4^{\circ}\right)$, isotonic saline and centrifuged at $750 \mathrm{~g}$ for $10 \mathrm{~min}$ at $4^{\circ}$. The washing procedure and centrifugation were repeated once more and the packed cells resuspended in isotonic saline. Portions of $1 \mathrm{ml}$ were taken for determination of erythrocyte superoxide dismutase $(E C 1.15 .1 .1)$ and glutathione reductase activity, and total erythrocyte thiamine concentration. These samples were centrifuged at $8800 \mathrm{~g}$ and the supernatant fraction removed. Samples for erythrocyte glutathione reductase (EGR) were resuspended in about $1 \mathrm{ml}$ distilled water.

Subsamples for measurement of alkaline phosphatase activity were placed at $4^{\circ}$ and analysed within $4 \mathrm{~h}$ of collection. All other subsamples were frozen immediately on solid $\mathrm{CO}_{2}$ and stored under liquid $\mathrm{N}_{2}\left(-196^{\circ}\right.$, EGR samples) or at $-40^{\circ}$ (all others).

\section{Biochemical measurements of micronutrient adequacy}

Iron. Haemoglobin concentration, packed cell volume, erythrocyte counts, and mean cell volume were measured (on the day of sampling) on an automated Coulter STKR counter ${ }^{\mathrm{TM}}$ 
(Coulter Electronics Ltd, Luton, Beds.) using Coulter's '4C-normal cell control' as quality control (QC). Serum ferritin, stored at $-40^{\circ}$, was determined within 6 months (the kit manufacturer's literature stating that samples could be stored for at least this time period even at the higher temperature of $-20^{\circ}$ ) with an ELISA procedure (Enzymum-Test Ferritin kit: Boehringer Mannheim Immunodiagnostics, Mannheim, Germany) using QC sera supplied with the ELISA kit.

Zinc and copper. Plasma samples $(2 \mathrm{ml})$ were deproteinized by mixing with $4 \mathrm{ml}$ of TCA (50 g/l, aqueous). Samples were centrifuged (2000 $\mathrm{g}$ for $10 \mathrm{~min}$ ) and stored as described earlier. $\mathrm{Zn}$ and $\mathrm{Cu}$ concentrations were determined using atomic absorption spectroscopy (PU 9100X, Phillips Ltd, Cambridge, Cambs.). QC for plasma $\mathrm{Zn}$ and $\mathrm{Cu}$ determinations was ensured via participation in the French Trace Element QC Assessment (organized by the Trace Element Group of the French Society of Clinical Biology) and use of an 'in-house' pooled plasma preparation which was prepared at the start of the study, stored with the samples and analysed with each batch of samples (inter- and intra-assay variation was $<5 \%$ ). Plasma alkaline phosphatase activity was determined colorimetrically, on the day of sampling, at $25^{\circ}$ using a kit assay (Test-combination Alkaline Phosphatase Kit, Boehringer Mannheim Diagnostica) and Precinorm ${ }^{\text {SM }}$ (Boehringer) as QC. Data were multiplied by 1.6 (according to the assay kit instruction sheet) to convert to assay units at $37^{\circ}$ before tabulation. Erythrocyte $\mathrm{Cu}$-dependent superoxide dismutase (CuSOD;) was determined by a spectrophotometric method based on the inhibition of superoxide generation by xanthine and xanthine oxidase (EC 3.2.1.8), (Randox Laboratories Ltd, County Antrim). QC was provided by an in-house washed-erythrocyte pool held under liquid $\mathrm{N}_{2}$.

Selenium. Whole-blood Se-dependent glutathione peroxidase (EC 1.11.1.9; Se-GSHPx) activity was measured using the modified procedure of Paglia \& Valentine (1967), as described by Whanger et al. (1988). QC was provided by an in-house whole-blood pool held under liquid $\mathrm{N}_{2}$. No loss of enzyme activity was observed after 1 year storage of whole blood at $-40^{\circ}$.

Vitamin C. Plasma ascorbic acid concentration was determined in metaphosphoric acid-stabilized samples (stored in liquid $\mathrm{N}_{2}$ ) using a HPLC method with electrochemical detection, modified from that of Behrens \& Madere (1987) and described fully elsewhere (Finglas et al. 1993). QC was provided by an in-house pool of plasma stabilized with metaphosphoric acid and held under liquid $\mathrm{N}_{2}$.

Vitamin $B_{I}$. Total erythrocyte thiamin concentration was determined using a normal phase HPLC technique following the oxidation of dephosphorylated thiamin to fluorescent thiochrome. Modified from Bailey \& Finglas (1990), the procedure is described fully by Bailey et al. (1994a). QC was provided by a stored pool of saline-washed erythrocytes.

Vitamin $B_{2}$. Erythrocyte glutathione reductase activity, basal and stimulated (with added coenzyme; flavine adenine dinucleotide) was determined using the method of Powers et al. (1983) and used to calculate the activation coefficient (EGR-Ac). QC was provided by repeat analysis of a batch of blood samples, held under liquid $\mathrm{N}_{2}$, having a wide span (approximately 1.0-1.5) of EGR-Ac values.

Vitamin $B_{6}$. Plasma PLP concentrations were measured by HPLC determination of their cyanide derivatives using the method of Naoi et al. (1988), with modifications as described previously (Bailey et al. 1994b; Southon et al. 1994). QC was provided by a stored pool of plasma. PLP is stable for up to 2 years storage at $-30^{\circ}$ (Borschel et al. 1987).

Vitamin $B_{12}$ and folate. Plasma vitamin $\mathrm{B}_{12}$ and 5-methyl tetrahydrofolic acid concentrations were determined (within 6 months of storage at $-40^{\circ}$ ) simultaneously by 
radioassay (Quantaphase vitamin B12/Folate radioassay; Bio-Rad Laboratories Ltd, Watford, Herts.) together with QC of Lyphocheck ${ }^{\mathrm{TM}}$ (levels 1, 2, and 3: Bio-Rad Ltd). Serum or plasma vitamin $B_{12}$ and folate stored at $-20^{\circ}$ have a shelf life of at least 2 years (Bio-Rad).

Vitamin D. Plasma 25-hydroxycholecalciferol (25-OH-D) concentrations were determined by radioimmunoassay (RIA) kit (Incstar Corp., Stillwater, MN, USA), QC samples being supplied with each assay kit. Samples can be stored for at least 6 months at a temperature below $-15^{\circ}$ (Incstar).

\section{Statistical analysis}

Statistical analysis was carried out using Minitab ${ }^{\mathrm{TM}}$. Data distributions were checked for normality using Shapiro-Francia ' $W$ ' tests of normality and where necessary data were transformed using $\log _{10}$ or $\sqrt{ }$. Details of the transformations used are shown in the tables of results. Means were compared using Student's $t$ test. The initial biochemical indices of subjects who were still alive after 2 years were compared with those of subjects who had died in the interim using $t$ tests. Biochemical indices measured at the start of the study period were compared with those measured after a 2 -year period using paired $t$ tests. The correlation between baseline and 2 year follow up data was examined by determining Pearson correlation coefficients.

Micronutrient intake and biochemical indices of nutritional adequacy were compared using analysis of covariance, taking into account other factors likely to influence individual biochemical measurements. Additional factors were only added if their inclusion in a model was statistically significant $(P<0.05)$. Age, smoking behaviour, alcohol and energy intake were considered in each analysis of covariance between intake and biochemical index. In addition the following variables were taken into account: for $\mathrm{Cu}$ and $\mathrm{Zn} ; \mathrm{Fe}$ intake, due to the possible competitive absorption of these three minerals (Lentner, 1984b; Hazell, 1985; Gibson, 1990); for vitamin $B_{6}$; protein intake, since vitamin $B_{12}$ is involved in protein metabolism (Gibson, 1990); for plasma folate; vitamin $B_{12}$ intake, since vitamin $\mathbf{B}_{12}$ deficiency is known to impair production of tetrahydrofolate (Gibson, 1990). Where the inclusion of such factors was found to increase the predictive value, the full equation including all predictive variables was generated, the residuals tested for normality and plotted against the data values and each predictive variable in turn to determine whether the analysis fitted the data.

Many of the ' $X$ ' variables ('predictor', nutrient intake) in the regression analysis were normalized, but a transformed ' $X$ ' variable is not unusual. Whilst recognizing that ' $X$ ' ('predictor') values do not need to be approximately normal, an underlying assumption of regression analysis is that the variability of ' $Y$ ' ('outcome') should be the same for each value of ' $X$ ' (Altman, 1991). The efficiency of nutrient absorption (giving rise to possible changes in biochemical status) is likely to decrease, and become more variable, with increasing intake. Thus it is more than likely that the variability of ' $\mathrm{Y}$ ' ('outcome' biochemical status) would increase with increasing intake and, hence, the use of normalized (transformed) nutrient intake is justified.

Although the numbers of male and female elderly subjects in each group were as large as practically feasible, they may still be regarded as statistically small sample sizes and therefore there is the possibility that biochemically significant differences or associations may not be found to be statistically significant. 


\section{RESULTS}

A larger proportion of men than women had died during the 2 years between assessments (eleven men, six women; $P<0.05$ ), but within a sex, age, weight and reported energy intake were closely comparable with those who remained alive. Baseline serum ferritin was lower $(P<0.01)$ in women who died (geometric mean, $24 \mu \mathrm{g} / 1)$ compared with survivors (geometric mean, $58 \mu \mathrm{g} / \mathrm{l}$ ) but not in men. No other differences were significant at $P<0.05$.

\section{Dietary intake}

Calculated mean daily intakes of energy and micronutrients are given in Tables 1 and 2 . Significant differences between sexes and percentages of subjects with intakes below the current UK reference nutrient intake (RNI), estimated average requirement (EAR) and lower reference nutrient intake (LRNI) are shown. There are no EAR or LRNI values for $\mathrm{Cu}$, biotin, pantothenic acid or vitamin D (Department of Health, 1991) and insufficient data were available to calculate Se intakes. Total energy, and hence micronutrient intake, was generally higher for males for all nutrients except vitamins C, D and thiamin. Women had a significantly higher intake of vitamin $C$ when nutrient intake was expressed per unit energy intake. Vitamin $B_{6}$ intake was highly correlated with protein intake $(r 0.76)$.

In order to assess whether reported energy intakes (EI) were an accurate measure of the food eaten during the study period without implying any systematic reduction in intake, estimates of BMR (BMR est ) were derived from Schofield's equations, which utilize sexand age-dependent multiplication factors of weight and height measurements (Schofield, 1985), and EI : BMR est ratios for each group were calculated. Goldberg et al. (1991) have published tables, adjusted for sample size and study duration, indicating what they consider to be minimum group $\mathrm{EI}: \mathrm{BMR}_{\text {est }}$ ratios compatible with reported energy intakes, being

Table 1. Mean daily energy and mineral intakes of the elderly population studied $\dagger$, and percentage of subjects with intakes below the reference nutrient intake (RNI), estimated average requirement (EAR) and lower reference nutrient intake (LRNI) (Department of Health, 1991, 1992)

(Mean values and standard deviations, with ranges in parentheses)

\begin{tabular}{|c|c|c|c|c|c|c|c|c|c|c|}
\hline \multirow[b]{2}{*}{ Nutrient } & \multicolumn{2}{|c|}{ Males ( $n 56)$} & \multicolumn{3}{|c|}{ \% Subjects below: } & \multicolumn{2}{|c|}{ Females ( $n$ 82) } & \multicolumn{3}{|c|}{ \% Subjects below: } \\
\hline & \multicolumn{2}{|c|}{ (Range) } & RNI & EAR & LRNI & Mean & (Range) & SNI & EAR & LRNI \\
\hline Energy $(\mathrm{MJ}) \ddagger$ & \multicolumn{2}{|c|}{$(3.465-14.862)$} & nv & 57 & nv & \multicolumn{2}{|c|}{$(3.745-10.700)$} & nv & 73 & nv \\
\hline Iron $(\mathrm{mg}) \S$ & \multicolumn{2}{|c|}{$(6.7-37.0)$} & 23 & 2 & 0 & \multicolumn{2}{|c|}{$(5 \cdot 3-38 \cdot 1)$} & 35 & 13 & 0 \\
\hline Copper $(\mathrm{mg}) \S$ & \multicolumn{2}{|c|}{$(0.72-7.30)$} & 18 & $\mathrm{nv}$ & nv & $\begin{array}{r}1.45 * * * \\
(0.52\end{array}$ & 0.84 & 48 & $\mathbf{n v}$ & $\mathrm{nv}$ \\
\hline Zinc (mg)\| & $\begin{array}{l}9.77 \\
(4.05\end{array}$ & $\begin{array}{l}2.80 \\
12)\end{array}$ & 50 & 16 & 2 & $\begin{array}{c}8 \cdot 11^{* * * *} \\
(3.89-1\end{array}$ & $\begin{array}{l}2 \cdot 24 \\
13)\end{array}$ & 28 & 13 & 1 \\
\hline
\end{tabular}

nv, No dietary reference value has been established (Department of Health, 1992).

Mean values were significantly different from those for males: ${ }^{* *} P<0.01,{ }^{* * *} P<0.001$.

†For details of subjects, see p. 226.

Transformation required to normalize distribution before comparison of the sexes: ‡none, $\S$ reciprocal, " $\log _{10}$. 
Table 2. Mean daily vitamin intakes of the elderly population studied $\dagger$, and percentage of subjects with intakes below the reference nutrient intake (RNI), estimated average requirement

(EAR) and lower reference nutrient intake (LRNI) (Department of Health, 1991, 1992)

(Mean values and standard deviations, with ranges in parentheses)

\begin{tabular}{|c|c|c|c|c|c|c|c|c|}
\hline \multirow[b]{2}{*}{ Nutrient } & Males ( $n$ 56) & \multicolumn{3}{|c|}{ \% Subjects below: } & Females ( $n$ 82) & \multicolumn{3}{|c|}{ \% Subjects below: } \\
\hline & $\begin{array}{r}\text { Mean SD } \\
\text { (Range) }\end{array}$ & RNI & EAR & LRNI & $\begin{array}{c}\text { Mean } \\
\text { (Range) }\end{array}$ & RNI & EAR & LRNI \\
\hline Vitamin C (mg) & $\begin{array}{cc}70 \cdot 2 & 37.0 \\
(24.5 & -169.4)\end{array}$ & 20 & 2 & 0 & $\begin{array}{cc}65.6 & 44 \cdot 1 \\
(14 \cdot 2-246 \cdot 2)\end{array}$ & 31 & 11 & 0 \\
\hline $\begin{array}{l}\text { Thiamin } \\
\quad(\mathrm{mg} / 4.2 \mathrm{MJ}(1000 \mathrm{kcal})) \S\end{array}$ & $\begin{array}{ll}0.67 & 0.20 \\
(0.35-1.27)\end{array}$ & 2 & 0 & 0 & $\begin{array}{c}0.72 \quad 0.25 \\
(0.40-1.95)\end{array}$ & 0 & 0 & 0 \\
\hline Riboflavin (mg) & $\begin{array}{cc}1.87 & 0.73 \\
(0.78-3.75)\end{array}$ & 25 & 4 & 2 & $\begin{array}{c}1.69 * * * \quad 0.57 \\
(0.67-3.26)\end{array}$ & 11 & 6 & 2 \\
\hline Vitamin $\mathrm{B}_{6}(\mu \mathrm{g} / \mathrm{mg}$ protein $) \ddagger$ & $\begin{array}{l}16.42 \quad 2.80 \\
(10.8-23.5)\end{array}$ & 29 & 9 & 2 & $\begin{array}{cc}17.48 * & 3.42 \\
(8 \cdot 87-26 \cdot 1)\end{array}$ & 24 & 6 & 4 \\
\hline Vitamin $B_{12}(\mu \mathrm{g}) \S$ & $\begin{array}{lr}5.01 & 3.57 \\
(1.88-23.34)\end{array}$ & 0 & 0 & 0 & $\begin{array}{cc}4.83^{* *} & 5 \cdot 20 \\
(0.85-38.38)\end{array}$ & 9 & 5 & 1 \\
\hline Folate $(\mu g)^{\|}$ & $\begin{array}{rr}174 & 58 \\
(79-320)\end{array}$ & 70 & 46 & 5 & $\begin{array}{c}149 * * \quad 46 \\
(65-267)\end{array}$ & 83 & 51 & 16 \\
\hline Vitamin D $(\mu \mathrm{g})^{\|}$ & $\begin{array}{lr}3.16 & 2.43 \\
(0.39-11.74)\end{array}$ & 0 & nv & nv & $\begin{array}{l}3.05 \quad 1.80 \\
(0.08-9.04)\end{array}$ & 9 & nv & $\mathrm{nv}$ \\
\hline $\begin{array}{l}\text { Niacin equivalents } \\
\text { (mg/4.2MJ }(1000 \mathrm{kcal}))\end{array}$ & $\begin{array}{l}17.84 \quad 3.96 \\
(11.79-30.81)\end{array}$ & $0 \dagger \dagger$ & 0 & 0 & $\begin{array}{cc}18.73 & 5.07 \\
(10.93-38.62)\end{array}$ & $0+1$ & 0 & $\mathbf{0}$ \\
\hline Biotin $(\mu g)$ & $\begin{array}{cr}23.46 & 8.52 \\
(9.90-59.30)\end{array}$ & 09 & nv & nv & $\begin{array}{cc}19.54 * * & 6.20 \\
(7.60-37.00)\end{array}$ & $4 \uparrow$ & nv & nv \\
\hline Pantothenic acid (mg) & $\begin{array}{ll}4.05 & 0.99 \\
(2.36-7.48)\end{array}$ & 299 & nv & nv & $\begin{array}{c}3.43 * * * \quad 0.94 \\
(1.53-5.99)\end{array}$ & $14 ף$ & nv & nv \\
\hline
\end{tabular}

nv, No dietary reference value (DRV) has been established (Department of Health, 1991, 1992).

Mean values were significantly different from those for males: ${ }^{*} P<0.05, * * P<0.01, * * * P<0.001$.

$\dagger$ For details of subjects, see p. 226.

Transformation required to normalize distribution before comparison of the sexes: $\ddagger$ none, $\S$ reciprocal, $" \log _{10}$.

ๆ No DRV has been set but guidelines are given: $10 \mu \mathrm{g}$ biotin/d and $3 \mathrm{mg}$ pantothenic acid/d are considered adequate for adults (Department of Health, 1992).

†† Niacin and tryptophan equivalents included (Department of Health, 1991).

plausible measures of actual dietary intakes during measurement periods. Elderly male and female ratios were $99 \%$ and $92 \%$ of the appropriate tabulated values respectively.

\section{Biochemical indices of micronutrient adequacy}

Values for a range of biochemical indices of trace mineral and vitamin nutritional adequacy are presented in Tables 3 and 4 respectively. Statistically significant differences between sexes, and percentage of subjects judged to have low biochemical indices of nutritional adequacy, as determined using currently used cut-off values for each micronutrient, are shown. Values below the cut-off points for risk of deficiency were found in a proportion of subjects for: haemoglobin and serum ferritin (Fe), plasma ascorbic acid, erythrocyte thiamin, EGR-Ac (riboflavin), plasma PLP (vitamin $\mathrm{B}_{6}$ ) and plasma folate. Plasma vitamin $B_{12}$ concentration was significantly correlated to plasma folate concentration in both sexes ( $r 0.90$ for men and 0.81 for women). 


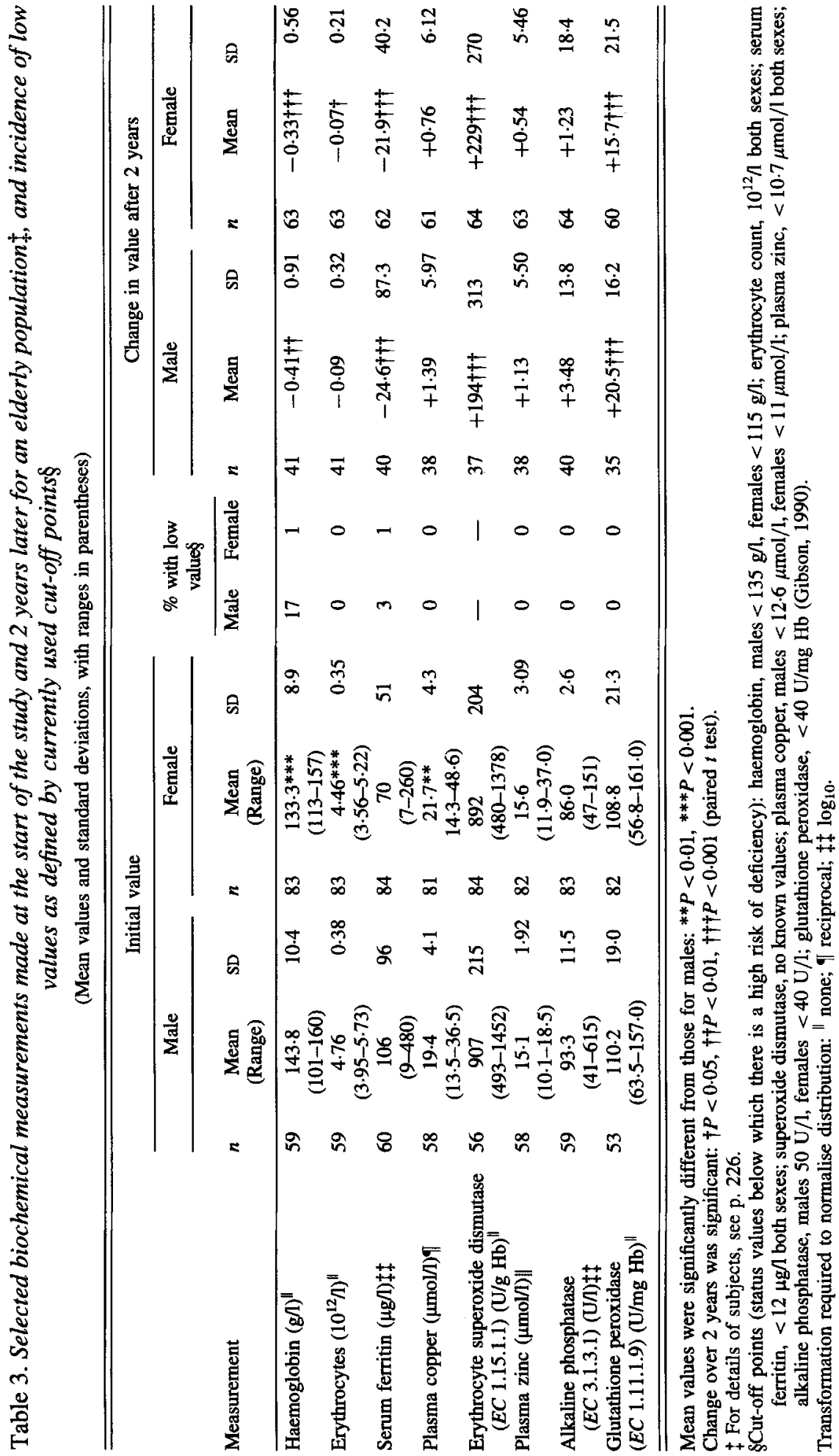




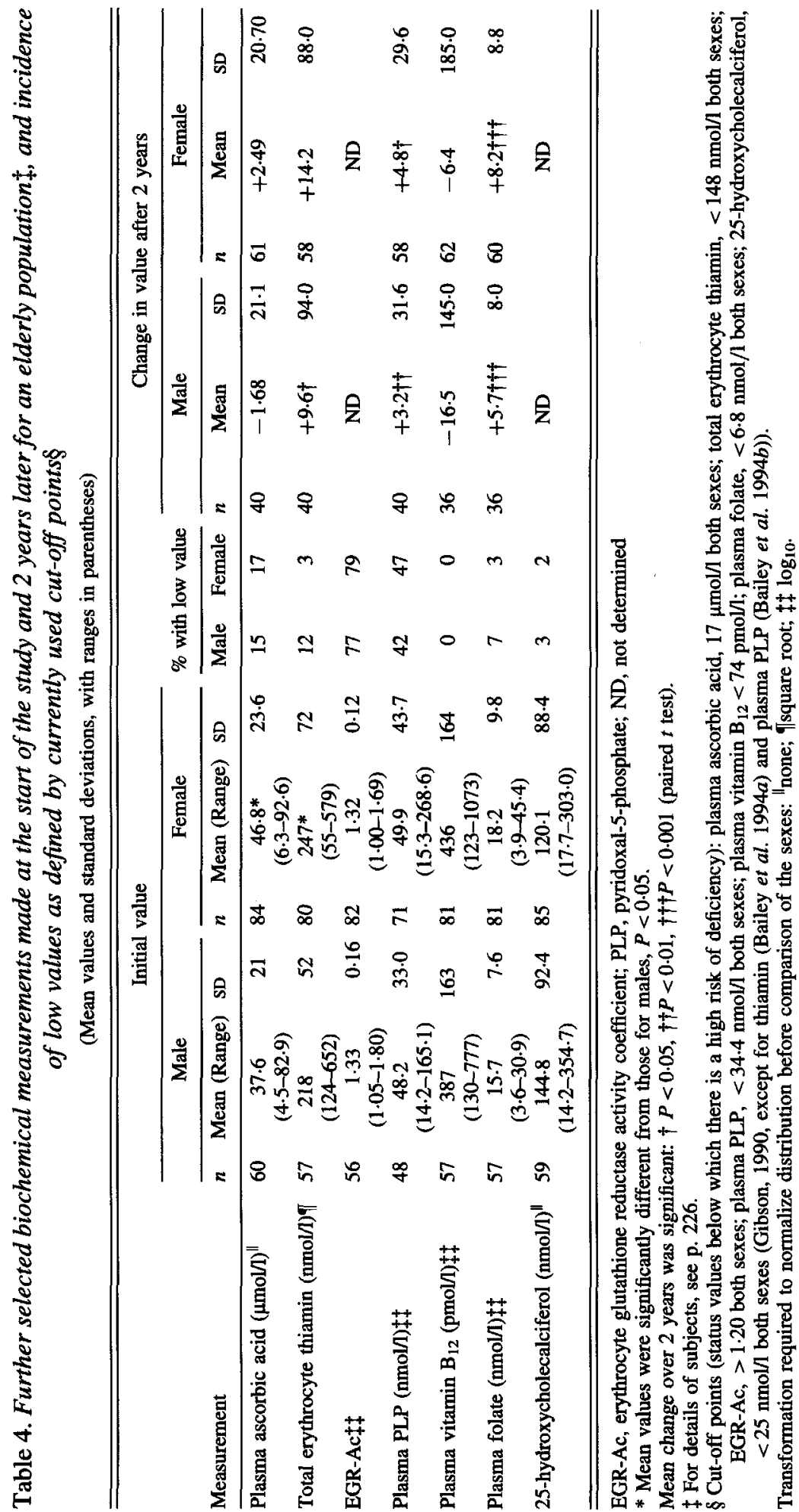


Vitamins A, E, K, niacin, biotin and pantothenic acid concentrations in plasma were not determined. However calculated intake data for niacin, biotin and pantothenic acid are presented in Table 2.

\section{Relationships between intake and biochemical indices of nutritional adequacy}

There was no significant relationship between calculated average dietary intake, within the range of intakes encountered in the present study, and plasma concentrations of $\mathrm{Cu}, \mathrm{Zn}$, vitamin $B_{6}$ and vitamin $B_{12}$. Furthermore, there was no relationship between $\mathrm{Cu}$ intake and measurements of the erythrocyte antioxidant enzyme $\mathrm{Cu}-\mathrm{SOD}$, nor was there a relationship between $\mathrm{Zn}$ intake and plasma alkaline phosphatase. No comparison of Se intake with whole-blood measurements of the antioxidant enzyme Se-GSH-Px was made since McCance and Widdowson's food composition tables (4th edition: Paul \& Southgate, 1978) have no listed values for Se. Significant relationships were found, however, for Fe, thiamin, riboflavin, folate, and vitamin $\mathrm{C}$. Equations that best describe these, with regression coefficients and levels of significance are shown in Table 5.

Table 5. Relationships found between micronutrient intake and biochemical measurements in an elderly population: equations for relationships found to be statistically significant $(\mathrm{P}<0.05)^{*}$

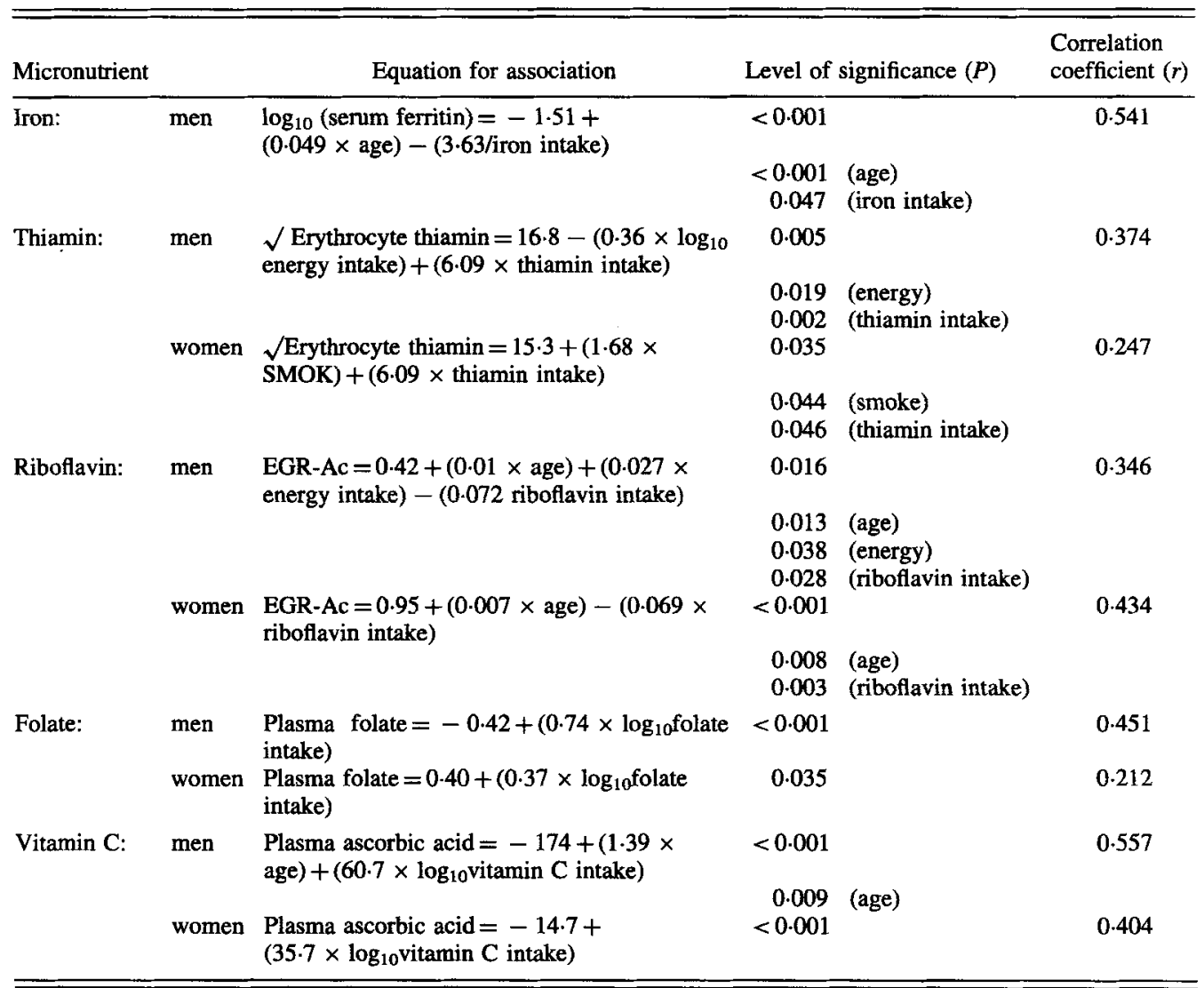

EGR-Ac, erythrocyte glutathione reductase activity coefficient; SMOK; smoking behaviour.

*Units: serum ferritin, $\mu \mathrm{g} / \mathrm{l}$; iron intake, $\mathrm{mg} / \mathrm{d}$; age, years; erythrocyte thiamin, $\mathrm{nmol} / \mathrm{l}$; thiamin intake, $\mathrm{mg} / \mathrm{d}$; energy intake, MJ/d; SMOK, binary variable $(1=$ smoker, $2=$ non-smoker $)$ EGR-Ac, no units; riboflavin intake, $\mu \mathrm{g} / \mathrm{d}$; plasma folic acid, $\mathrm{nmol} / \mathrm{h}$; folate intake, $\mu \mathrm{g} / \mathrm{d}$; plasma ascorbic acid, $\mu \mathrm{mol} / \mathrm{l}$; vitamin $\mathrm{C}$ intake, $\mathrm{mg} / \mathrm{d}$. 
Iron. There was a significant relationship between Fe intake and serum ferritin in men but only when age was taken into account. No association was observed in women. There was no significant relationship between Fe intake and haemoglobin or erythrocyte count, with or without inclusion of age, smoking behaviour, vitamin $\mathrm{C}$ or fibre intake.

Thiamin. Thiamin intake, not expressed per unit energy intake, was weakly but significantly related to total erythrocyte (RBC) thiamin in men $(P<0.05, r 0.29)$. The inclusion of energy intake improved the correlation $(P=0.005, r 0.41)$. The correlation of thiamin intake with erythrocyte thiamin was weaker for women and only became statistically significant when smoking was taken into account $(P=0.035, r 0.25)$.

Riboflavin. EGR-Ac was significantly correlated with riboflavin intake for both males and females. The association was improved when age and energy intake were included in the regression analysis; males $(P=0.016, r 0.35)$, females $(P<0.001, r 0.43)$.

Folate. Folate intake was significantly related to plasma folate in both men $(P<0.001$, $r 0.45)$ and women $(P=0.035, r 0.21)$. The inclusion of vitamin $\mathrm{B}_{12}$ intake did not help to predict folate values.

Vitamin $C$. Vitamin $\mathrm{C}$ intake and plasma ascorbate concentration were significantly correlated in men $(P<0.001, r 0.56)$ and women $(P<0.001, r 0.40)$. Inclusion of age in the equation improved the association for men only.

\section{Initial biochemical indices of nutritional adequacy as predictors of biochemical indices at 2 years}

Of those who declined to return for reassessment at 2 years, both men and women were slightly older, lighter, and reported lower energy intake than those who were reassessed, but none of these differences was statistically significant at $P<0.05$. Initial biochemical values, together with the change in value 2 years later, are shown in Tables 3 and 4 . Values for most of the biochemical measurements made at the start of the study correlated significantly $(P<0.05)$ with measurements made in the same group of individuals after 2 years (Table 6). A high correlation between an initial biochemical value and 2 year follow up does not, however, indicate that mean values are in agreement, and therefore correlations in Table 6 must be interpreted in conjunction with any change in mean biochemical value noted in Tables 3 and 4 . There was a significant relationship between initial and 2-year values for serum ferritin, haemoglobin, erythrocyte count, plasma alkaline phosphatase, plasma $\mathrm{Cu}$, plasma ascorbic acid, plasma PLP, EGR-Ac and plasma vitamin $B_{12}$ in both sexes, and for GSH-Px and erythrocyte $B_{1}$ in males only. Correlations were not statistically significant for SOD or plasma $\mathrm{Zn}$. However, there were significant differences in mean values between the two time points: serum ferritin and haemoglobin decreased and plasma folate, plasma PLP, GSH-PX and SOD increased in both sexes, erythrocyte count decreased in females and erythrocyte thiamin increased in males. There were no significant differences in biochemical values between the two time points for EGR-Ac or plasma alkaline phosphatase, plasma $\mathrm{Cu}$, plasma $\mathrm{Zn}$, plasma ascorbic acid or plasma vitamin $B_{12}$. Plasma vitamin $D$ was not measured at the 2 -year follow-up.

\section{DISCUSSION}

Results presented in this paper add to the limited information on biochemical measurements of micronutrient adequacy and deficiency in community elderly; a need highlighted in the report The Nutrition of Elderly People (Department of Health, 1992).

The mean dietary energy intakes of elderly men and women in the present study were similar to values reported in other larger studies (Department of Health, 1992). EI : BMR ratios calculated for our male and female subject groups, though similar to their adolescent 
Table 6. Initial micronutrient biochemical measurements as a predictor of results for the same measurements at 2 years in the elderly population studied*

\begin{tabular}{|c|c|c|c|c|c|c|c|}
\hline & \multirow[b]{2}{*}{ Biochemical status index measured } & \multicolumn{3}{|c|}{ Males } & \multicolumn{3}{|c|}{ Females } \\
\hline & & $n$ & $P$ & $\overline{r+}$ & $n$ & $P$ & $r \dagger$ \\
\hline \multirow[t]{8}{*}{ Minerals: } & Serum ferritin & 39 & $<0.001$ & 0.874 & 62 & $<0.001$ & 0.653 \\
\hline & Haemoglobin & 40 & $<0.001$ & 0.685 & 63 & $<0.001$ & 0.796 \\
\hline & Erythrocyte count & 40 & $<0.001$ & 0.830 & 63 & $<0.001$ & 0.828 \\
\hline & Plasma zinc & 38 & NS & & 63 & NS & \\
\hline & Plasma alkaline phosphatase ( $E C$ 3.1.3.1) & 48 & $<0.001$ & 0.865 & 68 & $<0.001$ & 0.666 \\
\hline & Plasma copper & 38 & $<0.001$ & 0.557 & 61 & $<0.001$ & 0.490 \\
\hline & Erythrocyte superoxide dismutase $(E C$ 1.15.1.1) & 37 & NS & & 64 & NS & \\
\hline & Whole-blood GSH-Px (EC 1.11.1.9) & 35 & $<0.01$ & 0.451 & 60 & NS & \\
\hline \multirow[t]{6}{*}{ Vitamins: } & Plasma ascorbic acid & 40 & $<0.01$ & 0.422 & 61 & $<0.001$ & 0.619 \\
\hline & Total erythrocyte thiamin & 40 & $<0.01$ & 0.404 & 58 & NS & \\
\hline & EGR-Ac $(E C$ 1.6.4.1) & 37 & $<0.02$ & 0.411 & 62 & $<0.01$ & 0.358 \\
\hline & Plasma pyridoxal phosphate & 40 & $<0.001$ & 0.710 & 58 & $<0.001$ & 0.540 \\
\hline & Plasma $B_{12}$ & 36 & $<0.001$ & 0.573 & 62 & $<0.001$ & 0.434 \\
\hline & Plasma folate & 36 & $<0.01$ & 0.491 & 60 & $<0.001$ & 0.547 \\
\hline
\end{tabular}

GSH-Px, glutathione peroxidase; EGR-Ac, erythrocyte glutathione activity coefficient.

* For details of subjects, see p. 226.

$\uparrow$ Correlations between initial and 2 year follow-up values should be considered in conjunction with absolute changes (Tables 3 and 4) since a high correlation for any biochemical index does not imply agreement between initial and 2-year follow up mean values.

and adult counterparts within the same community (Wright et al. 1995), implied some dietary under-reporting. However, this is not unusual, being in common with $64 \%$ of the studies employing weighed records studied by Black et al. (1991). Such results highlight the problems associated with placing too much reliance on nutrient intakes as a primary source of nutritional assessment. An assumption that any low group-mean energy intake is a result of 'general' under-reporting or systematic reduction in intake, rather than the omission of certain foods, would not preclude useful assessment of relationships between intake and biochemical measurements.

On the whole, the population studied here consumed adequate amounts of micronutrients, on the basis that mean intakes were above the current UK RNI (Department of Health, 1991). The exceptions to this were folate and vitamin D. However, the apparently high incidence of low folate intake could be explained (Finglas et al. 1990; Southon et al. 1992) by an underestimation of calculated food folate content when using the 4th edition of McCance and Widdowson's The Composition of Foods (Paul \& Southgate, 1978). Vitamin D is obtained principally from exposure to sunlight. The significance of low vitamin $\mathrm{D}$ intake in this elderly population will depend largely on their mobility and lifestyle, with dietary intake probably only being important to those that are housebound. There were a small number of subjects who had average daily nutrient intakes below the UK LRNI; two subjects for Zn, three subjects for riboflavin and one subject for vitamin $B_{12}$. If the intake data obtained were a true reflection of habitual intake, this suggests that these individuals were consuming inadequate amounts of these nutrients (Department of Health, 1991).

Low intakes were reflected in the incidence of low plasma concentrations only for vitamins $B_{2}$ and $B_{6}$. Subjects all appeared to have adequate plasma $\mathrm{Zn}$ and vitamin $\mathrm{B}_{12}$ concentrations, though these measurements are known to be insensitive; plasma $\mathrm{Zn}$ concentration is homeostatically controlled so that values associated with marginal 
deficiency states are usually within the normal range, and, in general, plasma vitamin $B_{12}$ concentration reflects liver storage content only when the latter falls to exceptionally low concentrations ( $<0.6 \mu \mathrm{g} / \mathrm{g}$ wet weight; Gibson, 1990).

A proportion of male and female subjects had a low serum ferritin concentration or low haemoglobin concentration (Table 3). Only one subject with a low serum ferritin concentration also had a low haemoglobin level. Although anaemia is much less common in the elderly than in younger population groups (Mertz, 1992), there does appear to be some risk in a small number of individuals, despite the total amount of Fe in the diet being adequate in comparison with UK recommendations. It is possible that the incidence of low haemoglobin and serum ferritin in the elderly is to some extent due to increased incidence of occult gastrointestinal bleeding. This can often be caused by increased use of nonsteroidal anti-inflammatory drugs (NSAID), rather than to dietary factors. However, in the present study (where $23 \%$ of both male and female subjects took NSAID regularly), there was no significant difference in haemoglobin or serum ferritin values between users and non-users of NSAID.

Complex dietary interactions and physiological factors are known to have a confounding effect on the relationship between total Fe intake and indices of body $\mathrm{Fe}$ stores. Thus, in studies of adolescent subjects (Southon et al. 1994) and adults (Wright $e t$ al. 1995) there was no relationship between Fe intake and serum ferritin concentration. In the present study of the elderly, a significant relationship between $\mathrm{Fe}$ intake and serum ferritin was observed in men when age was taken into account. This may have been the result of types and mixes of foods consumed. For example, this elderly group obtained more of their dietary $\mathrm{Fe}$ from meat and meat products and less from vegetables than younger age groups (J. Loughridge, unpublished results). On the other hand, the importance of the age factor in the Fe intake: serum ferritin concentration relationship indicates a possible difference in $\mathrm{Fe}$ metabolism. Mean haemoglobin concentration, erythrocyte counts and serum ferritin concentration were significantly lower when measured after 2 years, implying that although the risk of anaemia in the elderly is considered to be lower than in younger adults, this risk may increase slightly with advancing old-age. Serum ferritin concentration, haemoglobin, and erythrocyte counts were significantly correlated with values obtained at the 2-year follow-up, and thus appear to be good predictors of the longer-term situation.

Despite some elderly subjects having $\mathrm{Zn}$ intakes below the UK LRNI there was no evidence of $\mathrm{Zn}$ deficiency within the population as judged by plasma $\mathrm{Zn}$ concentrations. Alkaline phosphatase activities were also within the normal range for adults (Lentner, 1984a). Neither of these biochemical measurements, although commonly used, is a specific and sensitive index of tissue $\mathrm{Zn}$ concentration (Gibson, 1990). In the present study we found no relationship between $\mathrm{Zn}$ intake and either plasma $\mathrm{Zn}$ concentration or alkaline phosphatase activity, which was consistent with our observations in studies of adolescents and adults (Southon et al. 1994; Wright et al. 1995). These results contrast with those of Payette \& Gray-Donald (1991) who found a significant correlation between $\mathrm{Zn}$ intake and plasma $\mathrm{Zn}$ concentration in an elderly population, but $18 \%$ of their subjects had low plasma $\mathrm{Zn}$ concentrations, indicating the presence of a severe deficiency. In the present study, initial plasma $\mathrm{Zn}$ concentrations were not statistically correlated with those measured 2 years later. These results further emphasise the inability of plasma $\mathrm{Zn}$ to predict either short or longer-term $\mathrm{Zn}$ nutriture.

None of the subjects had a plasma $\mathrm{Cu}$ concentration below the accepted cut-off value for increased risk of deficiency. The occurrence of lower plasma $\mathrm{Cu}$ concentrations in male 
subjects is well documented (Lentner, 1984a). There was no relationship between $\mathrm{Cu}$ intake and either plasma $\mathrm{Cu}$ or SOD activity in this elderly population, nor was there in previous studies of adolescents and adults (Southon et al. 1994; Wright et al. 1995). As with plasma $\mathrm{Zn}$ concentration, plasma $\mathrm{Cu}$ is considered a relatively insensitive indicator of nutritional adequacy but, in contrast, plasma $\mathrm{Cu}$ concentrations at baseline and at follow-up were very similar indicating longer-term stability of this measurement.

The observation of an increase in antioxidant defence enzyme activity with time fits in with our earlier observation, in a cross-sectional study, that GSH-Px activity increased with age of subject (Wright et al. 1995). In the cross-sectional study no increase in SOD activity was observed with age but in the present study mean activity rose significantly between the initial and 2-year follow-up measurements. It is possible that in the present longitudinal study, which allowed comparison of paired data, more subtle effects have emerged. One possible explanation of this effect is that increased Se-GSH-Px activity is occurring in response to increased production of $\mathrm{H}_{2} \mathrm{O}_{2}$, as observed in animals with high expression of Cu-Zn-SOD (Ceballos-Picot et al. 1992). In an earlier paper we suggested that increased activity of these enzymes may be an indicator of imbalance in the regulation of oxygenderived free radicals with ageing (Wright $e$ t al. 1995). There was a significant correlation between baseline and follow-up values of GSH-Px activity for males only. No such correlation was found for SOD activity, though this may be a reflection of the larger relative standard deviation (RSD) associated with change in SOD activity over the 2-year interval.

Plasma ascorbic acid concentration was generally higher in women than men for similar intakes. Again, this sex difference is well documented (Lentner, 1984c; Wright $e t$ al. 1995). A proportion of subjects was found to have low plasma ascorbic acid concentration (indicative of high risk of deficiency) despite apparently adequate vitamin C intakes (in excess of the UK RNI; $40 \mathrm{mg} / \mathrm{d}$ ). This would suggest requirements higher than current recommendations in a significant number of our elderly subjects. There was a significant relationship between vitamin $\mathrm{C}$ intake and plasma ascorbic acid concentration, as found in other studies of adolescent and younger adult populations (Wright $e t$ al. 1995). Thus, despite all the complications of obtaining a reasonable estimate of vitamin $\mathrm{C}$ intake, including the relatively short period of dietary assessment used in this and other studies, vitamin stability problems and the often poor correlation between calculated and analysed intakes (Finglas et al. 1993), the relationship between vitamin C intake and plasma ascorbic acid appear to be relatively robust.

The incidence of low thiamin biochemical values observed in the present study should be considered cautiously, since cut-off values for total erythrocyte thiamin have not yet been firmly established (Bailey et al. 1994a). Erythrocyte transketolase activation coefficients (ETK-Ac) were not measured in the present study. In a previous study (Bailey et al. 1994a), ETK-Ac was found not to be correlated to either basal ETK (ETK ${ }^{\circ}$ ) or total erythrocyte thiamin, and although frequently used, ETK-Ac needs re-evaluation as an index of thiamin nutriture. The apparently large range of erythrocyte thiamin values for females results from two very high, and possibly spurious, values which were removed before statistical analysis. Neither of these subjects had an abnormal thiamin concentration on reassessment. Thiamin intake was only weakly associated with total erythrocyte thiamin, taking into consideration energy intake and age. A relationship was not found in adults or adolescents in a previously reported study (Bailey $e t$ al. 1994a).

Over $75 \%$ of subjects were at high risk of riboflavin deficiency as judged by EGR-Ac, whilst only three subjects consumed less than the UK LRNI for vitamin $B_{2}$. This supports the argument that elderly requirements are higher than the current recommendations 
(Russell, 1992). There was an inverse relationship between EGR-Ac and riboflavin intake for both males and females, whereas in adolescents a relationship was only found in females (Southon et al. 1994). Initial EGR-Ac were statistically correlated with those at 2 years for both sexes, indicating their value as a longer-term predictor.

Several studies have found elderly populations to have plasma PLP concentrations below the cut-off threshold for deficiency and it has been suggested that current dietary recommendations are insufficient for the elderly (Russell, 1992). In the present study almost half of the subjects had a low plasma PLP concentration. However, the cut-off concentration of $34.4 \mathrm{nmol} / \mathrm{l}$ was set somewhat arbitrarily (Rose et al. 1976) and, in view of the large numbers of our subjects (adolescent, adult and elderly) who could be classified as vitamin $\mathrm{B}_{6}$-deficient on the basis of plasma analysis (Southon et al. 1994; Wright et al. 1995), we suggest that the cut-off point for deficiency should be re-examined. The increase in PLP concentration over the 2-year study period is contrary to previously documented decreases in this index of vitamin $B_{6}$ with increased age (Lentner, 1984c). No significant relationship was found between vitamin $B_{6}$ intake and plasma PLP in this elderly group, although an association has been seen in adolescent males (Southon et al. 1994). Manore et al. (1989) also found a large prevalence of low plasma PLP and no relationship between vitamin $\mathrm{B}_{6}$ intake and plasma concentrations in free living, low income, elderly people. The observed relationship between vitamin $B_{6}$ intake and protein was expected, since this vitamin is found most commonly in foods that are also good protein sources (Paul \& Southgate, 1978). There was a significant correlation between initial plasma PLP and the same index recorded at the 2-year follow-up which is indicative of the value of plasma PLP measurement as a predictor of longer-term vitamin $B_{6}$ nutriture in the elderly.

Folate intake was weakly, but significantly, associated with plasma folate in both sexes. These relationships were not improved by inclusion of age, smoking behaviour, energy or alcohol intake or plasma vitamin $B_{12}$. Similar results have been reported for elderly by Payette \& Gray-Donald (1991). In contrast, no association between folate intake and plasma concentration was found in adolescents (Southon et al. 1994). However, in view of known problems with estimation of folate intake, any observed relationship between intake and biochemical measurements should be treated with some scepticism. The significant correlation between initial plasma folate and the same index after 2 years (for both sexes), suggests that such determinations have value in predicting long-term folate status.

There was no relationship between vitamin $B_{12}$ intake and plasma concentration. Vitamin $B_{12}$ is produced in considerable quantity by bacteria of the small intestine and colon (Gibson, 1990), although it is thought that probably only vitamin $\mathbf{B}_{12}$ synthesized in the region of the small intestine is absorbed (Albert et al. 1980). Absorption of vitamin $B_{12}$ in the ileum, is mediated by a gastric intrinsic factor. Differences in plasma vitamin $B_{12}$ may depend more on variations of the intrinsic factor synthesis and/or activity than any enterally produced vitamin $B_{12}$. Baseline and follow-up plasma vitamin $B_{12}$ concentrations were significantly correlated. Despite the significant correlation between plasma vitamin $B_{12}$ and plasma folate concentration, vitamin $B_{12}$ intake did not help to predict plasma folate concentration, nor did folate intake help to predict plasma vitamin $B_{12}$ concentration, which again may be a consequence of problems associated with folate intake assessment.

Many studies have shown reduced concentrations of plasma vitamin $D$ in the elderly (Russell, 1992) and these can occur for a variety of reasons: decreased intake, disturbances in vitamin $D$ metabolism and decreased ability to form provitamin $D_{3}$ on exposure to sunlight. Although the 25-OH-D concentrations found in the present study appeared essentially normal, there was a bimodal distribution of values. This was found to be related 
to the results from one batch of analyses which gave higher values. The variability of the kit assay (relative standard deviation $15 \%$ ) must be taken into consideration when interpreting results. In view of the lack of precision in this assay, plasma $25-\mathrm{OH}-\mathrm{D}$ concentration was not reassessed after 2 years.

\section{CONCLUSION}

The elderly population studied appeared to be adequately nourished with respect to $\mathrm{Cu}, \mathrm{Zn}$ and vitamin $B_{12}$, as judged by a range of biochemical measurements. A small proportion of subjects were identified as having low biochemical values with respect to $\mathrm{Fe}$, vitamin $\mathrm{C}$, folate and thiamin, and a larger proportion as having low biochemical values with respect to PLP (vitamin $\mathrm{B}_{6}$ ) and riboflavin. Lower biochemical values for Fe, thiamin, riboflavin, folate and vitamin $C$ were related to lower intakes, although not always for both sexes, and relationships were weak. Although consideration should be given to the requirements of the elderly for each of these micronutrients, perhaps particular attention should be focused on vitamin $\mathrm{C}$, where there is evidence to suggest an increased requirement in order to maintain circulating concentrations of plasma ascorbic acid (Wright et al. 1995), and riboflavin, where there is a high proportion of subjects apparently at risk of deficiency. The high proportion of elderly at apparent risk of vitamin $B_{6}$ deficiency may or may not be real, depending as it does on the arbitrary nature of the currently used cut-off value for plasma PLP. For all biochemical measurements performed, except SOD and plasma Zn, initial biochemical measurements were predictive of measurements made 2 years later, although mean values may have changed significantly.

This work was supported by the Ministry of Agriculture, Fisheries, and Food, the Department of Education and Science (now the Office of Science and Technology) and The Vitamin Forum. The authors thank Joanne Belsten, Zoe Piper, Julie Loughridge and Andrew Walker for invaluable assistance in this study, and Dr Christopher Bates and Brian Baker of the Medical Research Council, Dunn Nutrition Unit (Cambridge, Cambs.) for advice and use of equipment for the measurement of EGR-Ac. The authors would also like to thank all the subjects who gave their time and cooperation for this study, the doctors of Gurney Court and Tuckswood Surgeries who allowed us to recruit their patients and use their premises, the practice staff who helped in many ways, and the dietary interviewers.

\section{REFERENCES}

Albert, M. J., Mathan, V. I. \& Baker, S. J. (1980). Vitamin B12 synthesis by human small intestinal bacteria. Nature 283, 781-782.

Altman, D. G. (1991). Practical Statistics for Medical Research, p. 303. London: Chapman and Hall.

Bailey, A. L. \& Finglas, P. M. (1990). A normal phase high performance liquid chromatographic method for determination of thiamin in blood and tissue samples. Journal of Micronutrient Analysis 7, 147-157.

Bailey, A. L., Finglas, P. M., Wright, A. J. A. \& Southon, S. (1994a). Thiamin intake, erythrocyte transketolase activity and total erythrocyte thiamin in adolescents. British Journal of Nutrition 72, 111-115.

Bailey, A. L., Southon, S., Wright, A. J. A., Finglas, P. M. \& Maisey, S. (1994b). High performance liquid chromatographic determination of plasma pyridoxal-5-phosphate by use of the cyanide derivative. Proceedings of the Nutrition Society 53, 134A.

Behrens, W. A. \& Madere, R. (1987). A highly sensitive HPLC method for the estimation of ascorbic and dehydro-ascorbic acid in tissues, biological fluids and foods. Analytical Biochemistry 165, 102-107.

Black, A. E., Goldberg, G. R., Jebb, S. A., Livingstone, M. B. E., Cole, T. J. \& Prentice, A. M. (1991). Critical evaluation of energy intake data using fundamental principles of energy physiology. 2. Evaluating the results of published surveys. European Journal of Clinical Nutrition 45, 583-599.

Borschel, M. W., Kirksey, A. \& Hamaker, B. R. (1987). A micromethod for determination of plasma pyridoxal phosphate and its use in assessment of storage stability of the vitamer. Journal of Pediatric Gastroenterology and Nutrition 6, 409-413. 
Ceballos-Picot, I., Nicole, A. \& Sinet, P. M. (1992). Cellular clones and transgenic mice overexpressing copperzinc superoxide dismutase: models for the study of free radical metabolism and ageing. EXS 62, 89-98.

Crawley, H. (1988). Food Portion Sizes. London: H.M. Stationery Office.

Department of Health (1991). Dietary Reference Values for Food Energy and Nutrients for the United Kingdom. Report on Health and Social Subjects no. 41. London: H.M. Stationery Office.

Department of Health (1992). The Nutrition of Elderly People. Report on Health and Social Subjects no. 43. London: H.M. Stationery Office.

Finglas, P. M., Bailey, A., Walker, A., Loughridge, J. M., Wright, A. J. A. \& Southon, S. (1993). Vitamin C intake and plasma ascorbic acid concentration in adolescents. British Journal of Nutrition 69, 563-576.

Finglas, P. M., Wright, A. J. A., Faulks, R. M. \& Southgate, D. A. T. (1990). Revised folate content of UK vegetables - implications for intake. In Recent Knowledge on Iron and Folate Deficiencies in the World. Colloque INSERM no. 197, pp. 385-392 [S. Hercberg, P. Galan and H. Dupin, editors]. Paris: INSERM.

Gibson, R. S. (1990). Principles of Nutritional Assessment. Oxford: Oxford University Press.

Goldberg, G. R., Black, A. E., Jebb, S. A., Cole, T. J., Murgatroyd, P. R., Coward, W. A. \& Prentice, A. M. (1991). Critical evaluation of energy intake data using fundamental principles of energy physiology. 1. Derivation of cut-off limits to identify under-recording. European Journal of Clinical Nutrition 45, 569-581.

Hazell, T. (1985). Copper and zinc. World Review of Nutrition and Dietetics 46, 67-80.

Holland, B., Unwin, I. D. \& Buss, D. H. (1988). Cereals and Cereal Products. The 3rd Supplement to McCance and Widdowson's The Composition of Foods. Cambridge: Royal Society of Chemistry/MAFF.

Holland, B., Unwin, I. D. \& Buss, D. H. (1989). Milk Products and Eggs. The 4th Supplement to McCance and Widdowson's The Composition of Foods. Cambridge: Royal Society of Chemistry/MAFF.

Lentner, C. (1984a). Alkaline phosphatase. In Geigy Scientific Tables, vol. 3, pp. 186-187. Basle: Ciba-Geigy Ltd.

Lentner, C. (1984b). Blood-inorganic substances. In Geigy Scientific Tables, vol. 3, pp. 78-89. Basle: CibaGeigy Ltd.

Lentner, C. (1984c). Blood-vitamins. In Geigy Scientific Tables, vol. 3, pp. 125-134. Basle: Ciba-Geigy Ltd.

Maisey, S., Loughridge, J. M., Southon, S. \& Fulcher, R. (1995). Variation in food group and nutrient intake with day of the week in an elderly population. British Journal of Nutrition 73, 359-373.

Manore, M. M., Vaughan, L. A., Carroll, S. S. \& Lecklem, J. E. (1989). Plasma pyridoxal 5'-phosphate concentration and dietary vitamin $\mathrm{B}_{6}$ intake in free-living, low-income elderly people. American Journal of Clinical Nutrition 50, 339-345.

Mertz, W. (1992). Trace elements and ageing. In Nutrition of the Elderly. Nestlé Nutrition Workshop Series, vol. 29, pp. 145-149. [H. Munro and G. Schlierf, editors]. New York: Raven Press.

Naoi, M., Ichinose, H., Takahashi, T. \& Nagatsu, T. (1988). Sensitive assay for the determination of pyridoxal5-phosphate in enzymes using high performance liquid chromatography after derivatization with cyanide. Journal of Chromatography 434, $209-214$.

Paglia, D. E. \& Valentine, W. N. (1967). Studies on the quantitative and qualitative characteristics of erythrocyte glutathione peroxidase. Journal of Laboratory and Clinical Medicine 70, 158-169.

Paul, A. A. \& Southgate, D. A. T. (1978). McCance and Widdowson's The Composition of Foods, 4th ed. London: H.M. Stationery Office.

Payette, H. \& Gray-Donald, K. (1991). Dietary intake and biochemical indices of nutritional status in an elderly population, with estimates of the precision of the 7-d food record. American Journal of Clinical Nutrition $\mathbf{5 4}$, $478-488$.

Powers, H. J., Bates, C. J., Prentice, A. M., Lamb, W. H., Jepson, M. \& Bowman, H. (1993). The relative effectiveness of iron and iron with riboflavin in correcting microcytic anaemia in men and children in rural Gambia. Human Nutrition: Clinical Nutrition 37C, 413-425.

Rose, C. S., György, P., Butler, M., Andres, R., Norris, A. H., Shock, N. W., Tobin, J., Brin, M. \& Spiegel, H. (1976). Age differences in vitamin $B_{6}$ status of 617 men. American Journal of Clinical Nutrition 29, 847-853.

Russell, R. M. (1992). Micronutrient requirements of the elderly. Nutrition Reviews 50, 463-466.

Schofield, W. N. (1985). Predicting basal metabolic rate, new standards and reviews of previous work. Human Nutrition: Clinical Nutrition 39C, Suppl. 1, 5-41.

Southon, S., Wright, A. J. A., Finglas, P. M., Bailey, A. L. \& Belsten, J. L. (1992). Micronutrient intake and psychological performance of schoolchildren: considerations of the value of calculated nutrient intakes for the assessment of micronutrient status in children. Proceedings of the Nutrition Society 51, 315-324.

Southon, S., Wright, A. J. A., Finglas, P. M., Bailey, A. L., Loughridge, J. M. \& Walker, A. D. (1994). Dietary intake and micronutrient status of adolescents: effect of vitamin and trace element supplementation on indices of status and performance in tests of verbal and non-verbal intelligence. British Journal of Nutrition 71, 897918.

Tan, S. P., Wenlock, R. W. \& Buss, D. H. (1985). Immigrant Foods. The 2nd Supplement to McCance and Widdowson's The Composition of Foods. London: H.M. Stationery Office.

Whanger, P. D., Beilstein, M. A., Thomson, C. D., Robinson, M. F. \& Howe, M. (1988). Blood selenium and glutathione peroxidase activity of populations in New Zealand, Oregon and South Dakota. FASEB Journal 2 , 2996-3002. 
Wiles, S. J., Nettleton, P. A., Black, A. E. \& Paul, A. A. (1980). The nutrient composition of some dishes eaten in Britain: a supplementary food composition table. Journal of Human Nutrition 34, 189-223.

Wright, A. J. A., Southon, S., Bailey, A. L., Finglas, P. A., Maisey, S. \& Fulcher, R. A. (1995). Nutrient intake and biochemical status on non-institutionalized elderly subjects in Norwich: comparison with younger adults and adolescents from the same general community. British Journal of Nutrition 74, 453-475. 